\title{
The silane depletion fraction as an indicator for the amorphous/crystalline silicon interface passivation quality
}

\author{
A. Descoeudres, ${ }^{\text {a) }}$ L. Barraud, R. Bartlome, G. Choong, Stefaan De Wolf, F. Zicarelli, and \\ C. Ballif \\ Photovoltaics and Thin Film Electronics Laboratory, Institute of Microengineering (IMT), Ecole \\ Polytechnique Fédérale de Lausanne (EPFL), Rue A.-L. Breguet 2, 2000 Neuchâtel, Switzerland
}

(Received 1 September 2010; accepted 15 October 2010; published online 5 November 2010)

\begin{abstract}
In silicon heterojunction solar cells, thin amorphous silicon layers passivate the crystalline silicon wafer surfaces. By using in situ diagnostics during plasma-enhanced chemical vapor deposition (PECVD), the authors report how the passivation quality of such layers directly relate to the plasma conditions. Good interface passivation is obtained from highly depleted silane plasmas. Based upon this finding, layers deposited in a large-area very high frequency $(40.68 \mathrm{MHz})$ PECVD reactor were optimized for heterojunction solar cells, yielding aperture efficiencies up to $20.3 \%$ on $4 \mathrm{~cm}^{2}$ cells. () 2010 American Institute of Physics. [doi:10.1063/1.3511737]
\end{abstract}

Silicon heterojunction solar cells have a high conversion efficiency potential, ${ }^{1-5}$ up to $23 \%$ to date. ${ }^{6}$ The passivation of the crystalline silicon (c-Si) wafer surfaces is usually performed by very thin intrinsic amorphous silicon $(\mathrm{a}-\mathrm{Si}: \mathrm{H})$ layers, deposited by rf plasma-enhanced chemical vapor deposition (PECVD) (Refs. 2, 3, and 5) or similar methods [direct-current PECVD, ${ }^{3}$ hot-wire CVD (Ref. 4)]. The emitter and back surface field of the cell are formed either with PECVD doped a-Si:H or doped microcrystalline $(\mu \mathrm{c}-\mathrm{Si}: \mathrm{H})$ layers. It has been shown that a-Si:H can provide excellent passivation of c-Si surfaces. ${ }^{7-10}$ However, to produce highefficiency devices, it is crucial to control the properties of the a-Si:H layers during deposition. This task is usually difficult for heterojunction solar cells, because the layers thicknesses have to be kept very low, in the order of 10-15 nm. Since the properties of materials deposited by PEVCD are directly linked to the plasma properties, plasma diagnostics are very useful, giving fundamental insight into deposition mechanisms.

Properties of a-Si:H layers have already been studied in situ with optical methods. ${ }^{2,11}$ Here, an infrared laser-based plasma diagnostic tool is used in order to measure in situ the silane $\left(\mathrm{SiH}_{4}\right)$ depletion fraction during deposition. ${ }^{12}$ Silane depletion measurements have provided useful insights such as the origin of higher deposition rates when using very high frequency (VHF) ${ }^{13}$ the determination of the transition region between a-Si:H and $\mu \mathrm{c}-\mathrm{Si}: \mathrm{H}$ depositions, ${ }^{14}$ and the optimization of reactor configurations for fast equilibration at ignition. ${ }^{15}$ In this paper, the authors study the influence of the silane depletion on a-Si:H layers used for c-Si wafer passivation. Based on this study, heterojunction solar cells were optimized.

Amorphous silicon layers were deposited at $200{ }^{\circ} \mathrm{C}$ in an automated large-area (electrode size $50 \times 60 \mathrm{~cm}^{2}$ ), narrow-gap $(13 \mathrm{~mm})$, parallel-plate PECVD reactor powered at VHF $(40.68 \mathrm{MHz})$. This reactor is a modified version of an industrial KAI-M PlasmaBox ${ }^{\mathrm{TM}}$ reactor. ${ }^{16}$ It is equipped with a plasma impedance probe located between the matching network and the electrode power feed-in, measuring the active power $P_{\text {ac }}$ defined by

${ }^{a)}$ Electronic mail: antoine.descoeudres@epfl.ch.

$$
P_{\mathrm{ac}}=V_{\mathrm{rms}} I_{\mathrm{rms}} \cos \varphi
$$

where $V_{\text {rms }}$ and $I_{\text {rms }}$ are the root mean square values of the VHF excitation voltage and current, respectively, and $\varphi$ is the phase between them. Depending on the discharge regime, plasma polymerization leading to powder formation can occur. ${ }^{17}$ The presence of powder can be detected in the gas evacuation line of our reactor by visible laser light scattering (LLS). ${ }^{18}$ Optical emission spectroscopy (OES) completes further the characterization of the plasma properties.

The silane depletion fraction $D$ is defined by

$$
D=1-\frac{n_{\mathrm{SiH}_{4}}}{n_{\mathrm{SiH}_{4}}^{0}},
$$

where $n_{\mathrm{SiH}_{4}}^{0}$ and $n_{\mathrm{SiH}_{4}}$ are the silane densities in the reactor before plasma ignition and during the plasma steady state, respectively. At constant pressure, a fraction of the $\mathrm{SiH}_{4}$ molecules is dissociated by electron impact in the glow discharge into radicals and hydrogen, leading to a decrease in the initial density. These radicals contribute to some extent to the deposition of a-Si:H on the substrate and the reactor walls, the rest is pumped away or leads eventually to the formation of polysilane or powder. The silane density is deduced from light absorption spectroscopic measurements (the absorption is proportional to the density of the absorbing molecules). The monochromatic infrared light of a quantum cascade laser ${ }^{12,19}$ is focused and injected through the reactor itself, and the light intensity is measured on the other side. Measurements through the pumped reactor, through the reactor filled with silane at working pressure before ignition, and through the reactor during the steady-state discharge allow us to deduce the silane depletion $D$.

For passivation studies, intrinsic a-Si:H layers of about 15-20 $\mathrm{nm}$ were deposited on both sides of $300 \mu \mathrm{m}$ thick $n$-type $\langle 100\rangle$ float zone (FZ) c-Si wafers $(4 \Omega \mathrm{cm})$, using PECVD with pure silane flow plasmas. Just prior to deposition, native oxide on wafer surfaces was removed in an HF solution. Effective minority carrier lifetimes were measured as-deposited and after annealing $\left(180{ }^{\circ} \mathrm{C}\right.$ for $90 \mathrm{~min}$ in air) with a Sinton Consulting WCT-100 quasisteady-state photoconductance system. ${ }^{20}$ In addition, a-Si:H films were charac- 


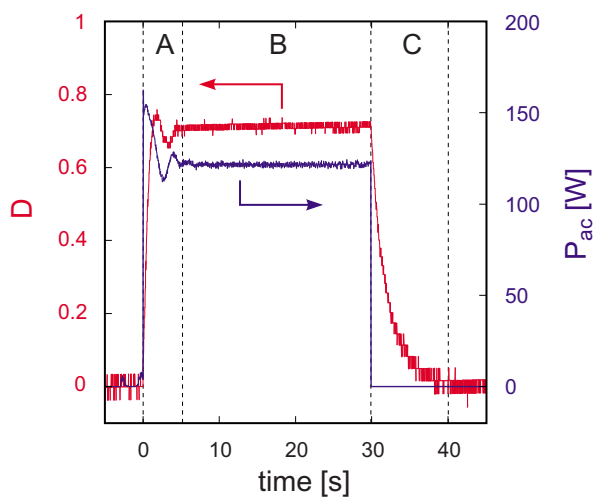

FIG. 1. (Color online) Example of time-resolved measurements of the silane depletion $D$ and of the active power $P_{\text {ac }}$ [120 SCCM (SCCM denotes cubic centimeter per minute at STP) $\mathrm{SiH}_{4}, 1$ mbar, $200 \mathrm{~W}, 30 \mathrm{~s}$ discharge, ignition at $t=0]$.

terized by spectroscopic ellipsometry. The structure of the $2 \times 2 \mathrm{~cm}^{2}$ heterojunction solar cells was as follows: Ag front grid/ $/ \mathrm{In}_{2} \mathrm{O}_{3}: \mathrm{Sn}$ (ITO) $80 \mathrm{~nm} / p^{+}$a-Si:H $10 \mathrm{~nm} / i$ a-Si:H $5 \mathrm{~nm} /$ textured FZ $n$ c-Si $300 \mu \mathrm{m} / i$ a-Si:H $5 \mathrm{~nm} / n^{+}$a-Si:H $10 \mathrm{~nm} /$ ITO $50 \mathrm{~nm} / \mathrm{Ag}$ back metallization. First, the $n$-type $\langle 100\rangle \mathrm{FZ}$ c-Si wafers were textured in $\mathrm{KOH}$, wet-chemically cleaned, and dipped in HF just before PECVD. Intrinsic and doped a-Si:H layers were deposited using mixtures of $\mathrm{SiH}_{4}, \mathrm{H}_{2}$, $\mathrm{PH}_{3}$, and $\mathrm{B}\left(\mathrm{CH}_{3}\right)_{3}$. Both ITO layers and the back metallization were deposited by dc magnetron sputtering. Finally, a front grid was screen-printed with a low temperature silver paste. All these fabrication steps are fully compatible for cell production at an industrial scale.

Figure 1 shows a time-resolved depletion measurement. The initial silane density drops at ignition because the gas is dissociated by the discharge. This increase in $D$ occurs here within the first second of the discharge but it can be even faster depending on the reactor configuration. ${ }^{15} \mathrm{~A}$ transient phase (A) is then observed during approximately the first $5 \mathrm{~s}$, where both $D$ and $P_{\text {ac }}$ are oscillating before stabilizing at a steady-state value (B). These oscillations are also observed in time-resolved OES acquisitions. As soon as the power is shut down, $D$ decays slowly to zero. This decrease during the afterglow occurs in roughly $10 \mathrm{~s}(\mathrm{C})$, the time for the radicals to be pumped away or to recombine.

Figure 2 shows the silane depletion fraction $D$, the active power $P_{\text {ac }}$ (steady-state values), the deposition rate $R$ and the effective minority carrier lifetime $\tau$ of the passivated wafers as a function of the three main process parameters, namely, the VHF input power, the silane flow and the total pressure (the effect of the deposition temperature was not investigated). Lifetime values are given at a minority carrier density of $10^{15} \mathrm{~cm}^{-3}$. In each panel of Fig. 2, only one process parameter was varied while the others were kept constant. Data are fitted only for the sake of clarity, and the fits do not have any physical meaning. It can be seen that $D$ depends strongly on the process parameters, going from 0.5 to 0.9 in the range of discharge regimes explored here. $D$ increases with the power because the silane dissociation rate is in first approximation proportional to the power, and $D$ decreases (increases) with the flow (pressure) because the $\mathrm{SiH}_{4}$ residence time in the reactor is decreased (increased). ${ }^{14}$ Whereas $R$ clearly increases with both the silane flow and the pressure, its behavior as a function of power is less obvious. An increase in $R$ with the power could be expected but in our case it saturates at $0.7 \mathrm{~nm} / \mathrm{s}$ above $300 \mathrm{~W}$. This is due to powder formation at this threshold, as confirmed by LLS measurements (not shown). The presence of powder was also clearly seen in time-resolved plasma impedance and OES measurements, with values strongly fluctuating in time, which is a signature of dusty regimes. ${ }^{21}$ Nevertheless, powder does not seem to be detrimental to the passivation quality. Lifetimes around $2.5 \mathrm{~ms}$ were indeed reached above $300 \mathrm{~W}$. It has even been shown elsewhere that $\mu \mathrm{c}-\mathrm{Si}: \mathrm{H}$ solar cell performances can actually improve when material is deposited in powderrich regimes. ${ }^{22}$

The minority carrier lifetime $\tau$ of as-deposited and annealed passivated wafers follows the same trend as $D$ in the power, silane flow, and pressure series. High lifetimes were obtained from highly depleted silane plasmas. In other words, passivation is improved with layers deposited close to microcrystalline regimes. ${ }^{14}$ This result can be linked to other silicon thin-film solar cell studies, where it is found that the best a-Si:H material quality is reached just before the a-Si:H to $\mu \mathrm{c}-\mathrm{Si}: \mathrm{H}$ transition. ${ }^{23,24}$ Thus, contrary to other plasma properties such as $P_{\text {ac }}$ or $R$ for example, a relevant parameter to characterize the passivating quality of a-Si:H layers appears to be the silane depletion. It is known that the structure of a-Si:H films depends on the plasma properties, mainly through the equilibration of the chemical potential of hydrogen in the plasma and in the film during growth. ${ }^{25}$ The a-Si:H/c-Si interface itself is also strongly affected by the hydrogen content and structure of the a-Si:H film. ${ }^{10,26}$ Since
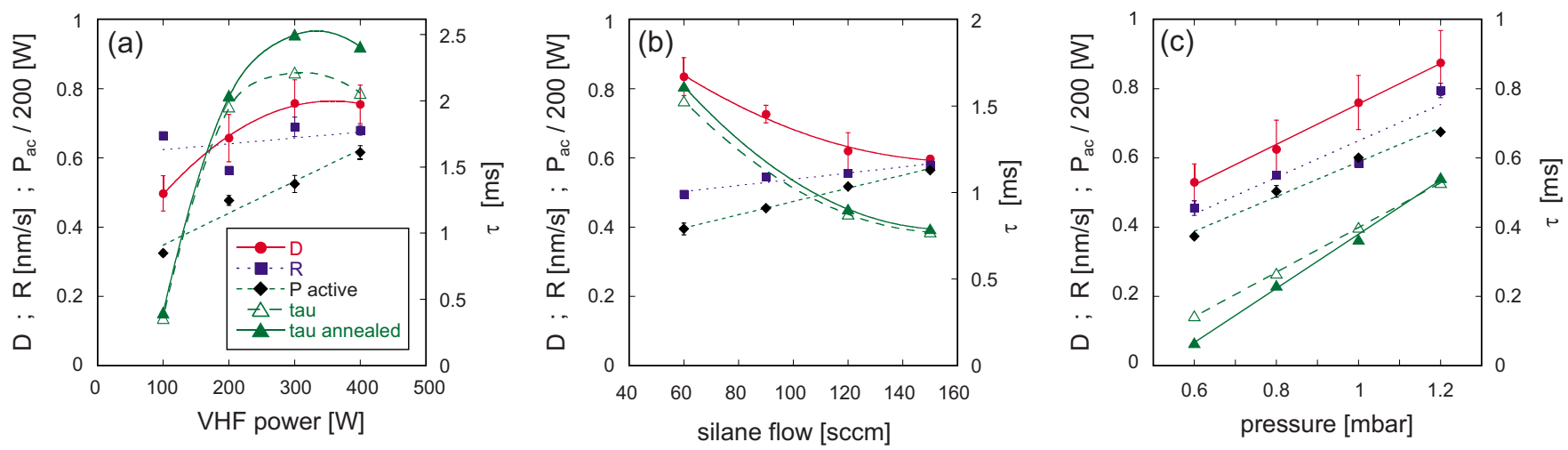

FIG. 2. (Color online) Depletion fraction $D$, deposition rate $R$, active power $P_{\text {ac }}$ and minority carrier lifetime $\tau$ as a function of (a) the VHF power (120 SCCM $\left.\mathrm{SiH}_{4}, 0.8 \mathrm{mbar}\right)$; (b) the silane flow $(200 \mathrm{~W}, 0.8 \mathrm{mbar})$; (c) the total pressure $\left(200 \mathrm{~W}, 120 \mathrm{SCCM} \mathrm{SiH}_{4}\right)$. Wafers are passivated with $18 \pm 3 \mathrm{~nm}$ intrinsic a-Si:H layers and are annealed at $180^{\circ} \mathrm{C}$ for $90 \mathrm{~min}$. Lines are guides for the eye. The legend in panel (a) applies to panel (b) and (c) as well. 


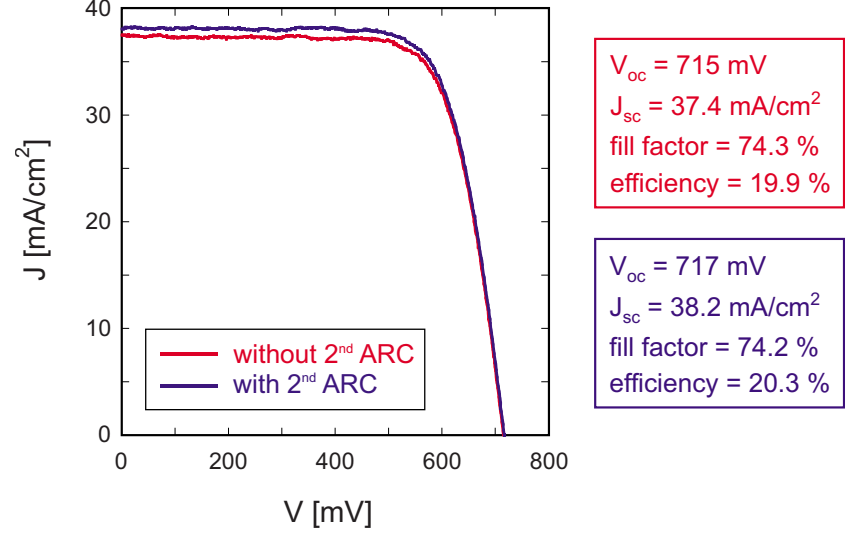

FIG. 3. (Color online) Illuminated-IV curve of the best $2 \times 2 \mathrm{~cm}^{2}$ heterojunction solar cell, measured under standard test conditions (in-house measurement).

hydrogen in the plasma plays such a critical role, it is clear that $D$ can be a physically relevant parameter for assessing the quality of the passivating layers. A detailed description of the link between depletion and passivation through hydrogen chemical reactions is, however, beyond the scope of this paper.

The passivation quality is highly sensitive to the reactor state before deposition (cleanliness, cross contamination, base vacuum level, history of preceding depositions, for example). Even with identical process parameters, the fluctuation of the lifetime absolute values can hence be high. Nevertheless, the trends of lifetime as a function of the process parameters presented here have been checked several times and are reproducible.

The optimization of passivating layers is thus greatly facilitated if one knows the silane depletion, since the three main process parameters can be reduced to only one, which in addition can be measured in situ during deposition. It should be noted that this optimization approach is not limited to pure silane flow plasmas but can also be applied for a-Si:H layers deposited from $\mathrm{H}_{2}$-diluted $\mathrm{SiH}_{4}$ flow plasmas for example.

Based on the results presented above, carrier lifetimes up to $4.8 \mathrm{~ms}$ (5.9 ms after annealing) were reached with $17 \mathrm{~nm}$ intrinsic a-Si:H layers on FZ polished wafers. This demonstrates that layers deposited at relatively high deposition rates $(>0.6 \mathrm{~nm} / \mathrm{s})$ with VHF can provide excellent passivation. As shown in Fig. 3 , the best $2 \times 2 \mathrm{~cm}^{2}$ cell obtained with our plasma-based optimization shows a high opencircuit voltage $\left(V_{\mathrm{oc}}\right)$ of $715 \mathrm{mV}$, giving an efficiency of $19.9 \%$ (aperture area). The addition of a $75 \mathrm{~nm}$ thick $\mathrm{MgF}_{2}$ second antireflection coating on top of the same cell improves mainly the short-circuit current density $\left(J_{\mathrm{sc}}\right)$, and increases the efficiency up to $20.3 \%$. The highest $V_{\text {oc }}$ measured in a cell reaches $720 \mathrm{mV}$.

In summary, the use of plasma diagnostics during PECVD is not only useful for a better understanding and control of the process but it is also highly valuable for the optimization of devices. We have shown that a-Si:H layers used for c-Si wafer passivation can be efficiently tuned knowing the silane depletion fraction during deposition. Indeed, it appears that the depletion is a much more relevant parameter than other plasma properties. In the discharge regimes explored here, good passivating layers were obtained from highly depleted plasmas. Produced in a large area industrial VHF PECVD reactor, medium-sized silicon heterojunction solar cells were optimized using this approach, yielding $20 \%$ efficiencies.

The authors acknowledge P. Bôle Rothen for her contribution to the work, Y. Andrault for wafer preparation, and Roth \& Rau Switzerland for many fruitful discussions. This work was supported by the Axpo Naturstrom Fond and by the European Commission (FP7 project HETSI, Grant No. 211821).

${ }^{1}$ M. Taguchi, K. Kawamoto, S. Tsuge, T. Baba, H. Sakata, M. Morizane, K. Uchihashi, N. Nakamura, S. Kiyama, and O. Oota, Prog. Photovoltaics 8, 503 (2000).

${ }^{2}$ H. Fujiwara and M. Kondo, J. Appl. Phys. 101, 054516 (2007).

${ }^{3}$ U. Das, M. Burrows, M. Lu, S. Bowden, and R. Birkmire, Appl. Phys. Lett. 92, 063504 (2008).

${ }^{4}$ Q. Wang, M. Page, E. Iwaniczko, Y. Xu, L. Roybal, R. Bauer, B. To, H.-C. Yuan, A. Duda, F. Hasoon, Y. Yan, D. Levi, D. Meier, H. Branz, and T. Wang, Appl. Phys. Lett. 96, 013507 (2010).

${ }^{5}$ B. Strahm, Y. Andrault, D. Baetzner, D. Lachenal, C. Guérin, M. Kobas, J. Mai, B. Mendes, T. Schulze, G. Wahli, and A. Buechel, Amorphous and Polycrystalline Thin-Film Silicon Science and Technology, MRS Symposia Proceedings (Materials Research Society, Warrendale, PA, 2010), p. A0104.

${ }^{6}$ M. Taguchi, Y. Tsunomura, H. Inoue, S. Taira, T. Nakashima, T. Baba, H. Sakata, and E. Maruyama, Proceedings of the 24th European Photovoltaic Solar Energy Conference, Hamburg, Germany, (WPI-Munich, Germany, 2009), p. 1690.

${ }^{7}$ J. Pankove and M. Tarng, Appl. Phys. Lett. 34, 156 (1979).

${ }^{8}$ S. Olibet, E. Vallat-Sauvain, and C. Ballif, Phys. Rev. B 76, 035326 (2007).

${ }^{9}$ S. De Wolf and M. Kondo, Appl. Phys. Lett. 90, 042111 (2007).

${ }^{10}$ S. De Wolf, S. Olibet, and C. Ballif, Appl. Phys. Lett. 93, 032101 (2008).

${ }^{11}$ J. J. H. Gielis, P. J. van den Oever, M. C. M. van de Sanden, and W. M. M. Kessels, Appl. Phys. Lett. 90, 202108 (2007).

${ }^{12}$ R. Bartlome, A. Feltrin, and C. Ballif, Appl. Phys. Lett. 94, 201501 (2009)

${ }^{13}$ L. Sansonnens, A. Howling, and C. Hollenstein, Plasma Sources Sci. Technol. 7, 114 (1998).

${ }^{14}$ B. Strahm, A. Howling, L. Sansonnens, and C. Hollenstein, Plasma Sources Sci. Technol. 16, 80 (2007).

${ }^{15}$ A. Howling, B. Strahm, P. Colsters, L. Sansonnens, and C. Hollenstein, Plasma Sources Sci. Technol. 16, 679 (2007).

${ }^{16}$ J. Perrin, J. Schmitt, C. Hollenstein, A. Howling, and L. Sansonnens, Plasma Phys. Controlled Fusion 42, B353 (2000).

${ }^{17}$ R. Ross and J. Jaklik, J. Appl. Phys. 55, 3785 (1984).

${ }^{18}$ R. Roth, K. Spears, G. Stein, and G. Wong, Appl. Phys. Lett. 46, 253 (1985).

${ }^{19}$ A. Müller and J. Faist, Nat. Photonics 4, 291 (2010).

${ }^{20}$ R. Sinton and A. Cuevas, Appl. Phys. Lett. 69, 2510 (1996).

${ }^{21}$ C. Hollenstein, Plasma Phys. Controlled Fusion 42, R93 (2000).

${ }^{22}$ G. Parascandolo, R. Bartlome, G. Bugnon, T. Soederstroem, B. Strahm, A. Feltrin, and C. Ballif, Appl. Phys. Lett. 96, 233508 (2010).

${ }^{23}$ G. Yue, D. Han, D. Williamson, J. Yang, K. Lord, and S. Guha, Appl. Phys. Lett. 77, 3185 (2000).

${ }^{24}$ R. Collins, A. Ferlauto, G. Ferreira, C. Chen, J. Koh, R. Koval, Y. Lee, J. Pearce, and C. Wronski, Sol. Energy Mater. Sol. Cells 78, 143 (2003).

${ }^{25}$ R. Street, Phys. Rev. B 43, 2454 (1991).

${ }^{26}$ T. F. Schulze, H. N. Beushausen, C. Leendertz, A. Dobrich, B. Rech, and L. Korte, Appl. Phys. Lett. 96, 252102 (2010). 